To cite this article: Anna-Leena Martikainen, Tuula Savinainen-Makkonen, \& Sari Kunnari (2020).

Speech inconsistency and its association with speech production, phonological awareness and nonword repetition skills. Clinical Linguistics \& Phonetics, DOI: 10.1080/02699206.2020.1827296

Speech inconsistency and its association with speech production, phonological awareness and nonword repetition skills

\author{
Anna-Leena Martikainen ${ }^{\mathrm{a} *}$, Tuula Savinainen-Makkonen ${ }^{\mathrm{a}}$, and Sari \\ Kunnari $^{\mathrm{a}}$ \\ ${ }^{a}$ Logopedics, University of Oulu, Oulu, Finland
}

*Anna-Leena Martikainen, University of Oulu, Faculty of Humanities, Logopedics, PO Box 1000, 90014 University of Oulu, Finland

Email: anna-leena.martikainen@student.oulu.fi

Telephone: +358443664744 
To cite this article: Anna-Leena Martikainen, Tuula Savinainen-Makkonen, \& Sari Kunnari (2020). Speech inconsistency and its association with speech production, phonological awareness and nonword repetition skills. Clinical Linguistics \& Phonetics, DOI: 10.1080/02699206.2020.1827296

\section{Speech inconsistency and its association with speech production, phonological awareness and nonword repetition skills}

The purpose of this study was to investigate relationships between speech inconsistency, speech production skills, phonological awareness and nonword repetition (NWR) in 24 preschool-aged Finnish-speaking children with speech sound disorder (SSD) and in 31 children with typical speech and language development (TD). Speech inconsistency was assessed by a picture-naming task repeated three times during one assessment session. The participants' speech production skills were assessed with the Finnish Test for Phonology and a diadochokinetic (DDK) task. Phonological awareness was investigated by the tasks of Rhyme and initial syllable awareness and Syllable segmentation, and NWR by ten 2-4-syllabic nonwords. The findings indicated that the children with SSD were less accurate in speech production and NWR than the children with TD. No difference was found in phonological awareness. Among the children with SSD, speech inconsistency was correlated with accuracy in overall speech production, DDK task, and NWR. Among the children with TD, speech inconsistency was correlated with accuracy in overall speech production, partly with phonological awareness, and with NWR. The results provide support for the idea that when assessing speech inconsistency in children with SSD, a process-oriented approach may be needed in order to obtain an adequately broad picture of their skill profiles. 
To cite this article: Anna-Leena Martikainen, Tuula Savinainen-Makkonen, \& Sari Kunnari (2020). Speech inconsistency and its association with speech production, phonological awareness and nonword repetition skills. Clinical Linguistics \& Phonetics, DOI: 10.1080/02699206.2020.1827296

Keywords: diadochokinesia; nonword; phonological awareness; speech inconsistency; speech sound disorder

\section{Introduction}

Inconsistency in speech production, also called token-to-token inconsistency, i.e. pronouncing a word in multiple ways within a short time period, is considered to be a feature of impaired speech development (e.g. Holm, Crosbie, \& Dodd, 2007; Martikainen, Savinainen-Makkonen, Laukkanen-Nevala, \& Kunnari, 2020), particularly in childhood apraxia of speech (American Speech-Language-Hearing Association, 2007) and inconsistent speech disorder (Dodd, Holm, Crosbie, \& McCormack, 2005). However, the significance of inconsistency may be difficult to determine, as intra-word variability can also be a part of typical speech development (e.g. Macrae, 2013; Sosa \& Stoel-Gammon, 2006) and it is argued to be highly prevalent even in those ages when children are typically referred to an assessment due to concerns about their speech development (Macrae \& Sosa, 2015; Sosa, 2015; but see also Holm et al., 2007; Martikainen, Savinainen-Makkonen, \& Kunnari, 2019). Research on variable speech production so far is mainly conducted among children acquiring English and their results are partly mixed (e.g. Holm et al., 2007; Macrae \& Sosa, 2015; Martikainen et al., 2020; Sosa, 2015). In order to deepen our knowledge of underlying nature of speech inconsistency, further studies are warranted. Especially research on typologically different languages might bring out new viewpoints to the phenomenon.

Inconsistency of speech has been explained both from a motoric and linguistic viewpoint. In motor development, variability is regarded as an essential element (see Hadders-Algra, 2018 for a review). It is believed to enable the adaptation of new behaviours and the accommodation of the speech motor system, for example to growth 
To cite this article: Anna-Leena Martikainen, Tuula Savinainen-Makkonen, \& Sari Kunnari (2020). Speech inconsistency and its association with speech production, phonological awareness and nonword repetition skills. Clinical Linguistics \& Phonetics, DOI: 10.1080/02699206.2020.1827296

of the vocal tract and different phonetic contexts of words (Whiteside, Dobbin, \& Henry, 2003). A number of studies have shown that articulatory movements of young children with typical speech and language development (TD) are variable and become more stable with age (e.g. Green, Moore, \& Reilly, 2002; Smith \& Goffman, 1998). Among children with speech sound disorder (SSD), variability has been reported to be even more pronounced (Terband, Maassen, van Lieshout, \& Nijland, 2011; Vuolo \& Goffman, 2016). Given these findings, it would be logical to conclude that variability of speech arises from unstable articulatory movements, but no evidence has been found to support a connection between segmental level accuracy or variability, and movement variability (Goffman, Gerken, \& Lucchesi, 2007; Vuolo \& Goffman, 2016).

Findings of a connection between overall speech production skills, i.e. segmental level accuracy, and speech inconsistency are mixed. Macrae and Sosa (2015) found no relationship between accuracy of consonants measured by an articulation test (GFTA) and intra-word variability in children with TD aged 2;6 to 4;2. As GFTA is primarily used to assess children suspected of having SSD, the authors speculated that the test might not be sufficiently sensitive for measuring speech production skills among children with TD. Martikainen et al. (2019) studied the correlation between speech inconsistency and accuracy of consonants and vowels derived from a conversational speech sample in children with TD aged 3;0-6;11. The data were analysed at the phonemic level (i.e. substitutions, deletions and additions were considered as errors) and no correlation was found when the effect of age was controlled. This was assumed to be a consequence of a ceiling effect due to the participants' good phonological skills. In a subsequent study on children with TD aged 3;2-5;4, Martikainen et al. (2020) found, however, that responses which did not include correct forms at all in the intra-word variability measure were related to inaccuracy of 
To cite this article: Anna-Leena Martikainen, Tuula Savinainen-Makkonen, \& Sari Kunnari (2020). Speech inconsistency and its association with speech production, phonological awareness and nonword repetition skills. Clinical Linguistics \& Phonetics, DOI: 10.1080/02699206.2020.1827296

consonants in spontaneous speech. In their study, data were analysed at the phonetic level (i.e. distortions were also considered as errors). The authors observed that the level of transcription can be significant when tracking connections to the motor subsystems of speech. Among children of the same age range (i.e. 3;2-5;4) with SSD, it was found that not only inaccurate production of consonants but also inaccurate production of vowels in spontaneous speech were correlated with inconsistent responses (Martikainen et al., 2020). In order to investigate this connection further, the authors proposed the use of a diadochokinetic task (DDK), which might reflect more clearly the role of motor subsystems in inconsistent speech production.

It has been stated that DDK, i.e. repetition of non-meaningful syllable strings, is free from linguistic issues and thus reflects predominantly neuromotor aspects of speech production. Traditionally, researchers have been interested in the rate of repetitions (Diepeveen, van Haaften, Terband, de Swart, \& Maassen, 2019; Thoonen, Maassen, Gabreels, \& Schreuder, 1999), but it has been suggested that accuracy and consistency of production might also be worthy of consideration (Preston \& Edwards, 2009; Williams \& Stackhouse, 2000). Williams and Stackhouse (2000) reported that accuracy of syllable sequence repetitions typically increased with age in children with TD aged 3-5. There was, however, considerable variation in performance among the youngest children and the role of accuracy in an assessment of speech production in that age group was questioned. Consistency of repetitions, on the other hand, improved significantly between 3 and 4 years of age. Children with childhood apraxia of speech (CAS) have particular problems in producing correct sequences of /pataka/, which is considered as an important diagnostic sign of CAS (Murray, McCabe, Heard, \& Ballard, 2015; Thoonen et al., 1999). 
To cite this article: Anna-Leena Martikainen, Tuula Savinainen-Makkonen, \& Sari Kunnari (2020). Speech inconsistency and its association with speech production, phonological awareness and nonword repetition skills. Clinical Linguistics \& Phonetics, DOI: 10.1080/02699206.2020.1827296

From the linguistic viewpoint, speech inconsistency has been proposed to relate to poorly specified phonological representations of words. This is concluded from the association between inconsistent speech production and poor vocabulary knowledge both in children with TD and children with SSD, although findings are mixed (Dodd et al., 2005; Macrae, Tyler, \& Lewis, 2014; Macrae \& Sosa, 2015; Martikainen et al., 2019; Martikainen et al., 2020). The term "phonological representation" refers to storage of a word's phonological features in long-term memory. According to the lexical structuring model (Metsala \& Walley, 1998), these representations are underspecified when children begin to acquire spoken language but will gradually become more refined simultaneously with growing vocabulary. There is also a divergent view, which argues that phonological information is detailed even from early childhood on (e.g. Swingley \& Aslin, 2000). In any case, compared to children with TD, children with SSD have been found to have poorer abilities to form, access and fine-tune phonological representations of words (Anthony et al., 2011; McNeill, Gillon, \& Dodd, 2009; Sutherland \& Gillon, 2007). It has been proposed that the quality of phonological representations may be reflected in the accuracy of a child's speech production (Elbro, Borstrom, \& Petersen, 1998). Contrary to that it has also been asserted that the process of fine-tuning primary holistic phonological representations into segmentally organized representations may be dependent on the accuracy of articulation (Carroll, Snowling, Stevenson, \& Hulme, 2003).

There is some support for the idea that both phonological awareness (Anthony et al., 2011; Elbro et al., 1998; Rvachew, 2006; Sutherland \& Gillon, 2007) and nonword repetition (NWR) tasks (Edwards, Beckman, \& Munson, 2004) can provide implicit information about children's phonological representations. Phonological awareness is a broad term which refers to a child's ability to shift attention from the meaning of words 
To cite this article: Anna-Leena Martikainen, Tuula Savinainen-Makkonen, \& Sari Kunnari (2020). Speech inconsistency and its association with speech production, phonological awareness and nonword repetition skills. Clinical Linguistics \& Phonetics, DOI: 10.1080/02699206.2020.1827296

to their sound structure. This development generally proceeds from a word- and syllable-level sensitivity to rhyme and onset level skills and, finally, to the ability to access and manipulate individual phonemes of words, i.e. to phonemic awareness (Carroll et al., 2003). Development of phonemic awareness skills is stated to be based on vocabulary growth (e.g. Edwards et al., 2004; Walley, Metsala, \& Garlock, 2003). It is well established that children with SSD often have poorer phonological awareness skills than children with TD (Anthony et al., 2011; Brosseau-Lapré \& Roepke, 2019; Larrivee \& Catts, 1999; McNeill et al., 2009; McNeill, Wolter, \& Gillon, 2017; Peterson, Pennington, Shriberg, \& Boada, 2009; Preston \& Edwards, 2010). This is explained by the presence of a comorbid language impairment and the persistence and/or severity of the SSD (Larrivee \& Catts, 1999; McNeill et al., 2017; Peterson et al., 2009). Furthermore, patterns of speech sound errors have been demonstrated to be associated both with phoneme awareness and with phonological awareness in general (Brosseau-Lapré \& Roepke, 2019; Dodd et al., 2005; Holm, Farrier, \& Dodd, 2008; McNeill et al., 2017; Preston \& Edwards, 2010).

NWR was originally used to assess short term memory skills (Gathercole \& Baddeley, 1989). More recently it has been shown that NWR taps a number of linguistic processing skills and cognitive processes (see Coady \& Evans, 2008 for a review): perceiving the acoustic signal, segmenting it into speech units, forming a phonological representation on that basis and holding it temporarily in the working memory in order to plan and program motoric gestures for it, and finally executing the program. With respect to speech inconsistency, Macrae et al. (2014) found that the more variable speech errors children with SSD (aged 3;6-5;5) produced, the poorer were their NWR results. The authors interpreted this to support an account of indistinct underlying phonological representations. 
To cite this article: Anna-Leena Martikainen, Tuula Savinainen-Makkonen, \& Sari Kunnari (2020). Speech inconsistency and its association with speech production, phonological awareness and nonword repetition skills. Clinical Linguistics \& Phonetics, DOI: 10.1080/02699206.2020.1827296

\section{Some characteristics of Finnish phonology}

In order to understand a possible influence of language-specific characteristics on the factors which might interrelate with inconsistent speech production, it is necessary to review some basic phonological facts of the Finnish language. The Finnish phoneme repertoire consists of 13 consonants and 8 vowels. At the age of 3;0, all the vowels and consonants, except /d/ and /r/ are mastered (Kunnari, Savinainen-Makkonen, \& Saaristo-Helin, 2012). By the age of 5;0, also /d/ and /r/ are acquired although there may still be some phonetic variation (Kunnari et al., 2012). Word-initial and word-final consonant clusters are rare in Finnish, but word-medial hetero-syllabic consonant clusters (i.e. consonant sequences across a syllable boundary such as lin.tu 'bird', help.po 'easy') are common. The syllable types CV, CVC and CVV are the most common syllable structures in early words in children (Kunnari, 2000). Monosyllabic words are rare. Bisyllabic words are the most frequent, and trisyllabic words and longer are also common (Karlsson, 1983). Typically developing children can use correct word length even in longer words by age of 3;6 (Aalto et al., 2019; Kunnari et al, 2012; Saaristo-Helin, 2009).

\section{Current study}

Based on previous studies, phonological representations have arisen as a strong candidate as a source of inconsistent speech production. However, in view of the findings of Martikainen et al. (2020), speech production skills may also have a role in this process. In this work, we examined the association of speech inconsistency with speech production, phonological awareness and nonword repetition skills in preschoolaged children. Better understanding of these associations might allow speech and language therapists to refine both the assessment protocols and target selection 
To cite this article: Anna-Leena Martikainen, Tuula Savinainen-Makkonen, \& Sari Kunnari (2020). Speech inconsistency and its association with speech production, phonological awareness and nonword repetition skills. Clinical Linguistics \& Phonetics, DOI: 10.1080/02699206.2020.1827296

strategies used in intervention. We hypothesised that speech production skills of children with TD would be better than those of children with SSD. We reasoned that these skills would correlate negatively with the children's scores on the intra-word variability measure. In other words, the better the children's speech production skills, the less inconsistent they are. We also reasoned that the phonological awareness skills of the children with SSD would be poorer than those of the children with TD. We expected negative correlation between phonological awareness and inconsistent speech production among both study groups. Furthermore, we hypothesised that NWR would be more challenging for the children with SSD than for the children with TD, and that difficulties in NWR would further be reflected in difficulties in accurately producing words in the intra-word variability measure. In order to shed some light on the role of different underlying factors of nonword repetition in inconsistent speech production, correlation of nonword repetition with speech production skills and phonological awareness was examined. Our hypothesis was that NWR would be correlated both with speech production and phonological awareness skills.

\section{Method}

\section{Participants}

Two groups participated in this study: a group of children with SSD and a group with TD. Participants were recruited through public notices at child welfare centres and in a local newspaper, and via an information letter to heads of early childhood education centres. All the participants were required to demonstrate normal receptive language skills, as evidenced by a standard score of 85 or more on the Reynell Developmental Language Scales (Kortesmaa, Heimonen, Merikoski, Warma, \& Varpela, 2001), and no more than

1 SD below the mean on the Receptive One-Word Picture Vocabulary Test -4 
To cite this article: Anna-Leena Martikainen, Tuula Savinainen-Makkonen, \& Sari Kunnari (2020). Speech inconsistency and its association with speech production, phonological awareness and nonword repetition skills. Clinical Linguistics \& Phonetics, DOI: 10.1080/02699206.2020.1827296

(ROWPVT-4, Martin \& Brownell, 2010). Furthermore, normal oro-motor skills, no reported neurological diseases, and use of Finnish as a primary language were required. Normal nonverbal intelligence among the children with SSD was evidenced by a standard score no more than 1 SD below the mean on the Leiter International Performance scale3rd Edition (Roid, Miller, Pomplun, \& Koch, 2013) and among the children with TD by a parent and teacher report. In addition, the children had to have normal hearing, as evidenced among the children with SSD by passing a hearing screening at $20 \mathrm{~dB} \mathrm{HL}$ at 500, 1000, 2000 and $4000 \mathrm{~Hz}$ and among the children with TD by parent reporting that the children had passed annual hearing screening tests at a local child welfare clinic. Inclusion criteria for the two groups were a score below the $16^{\text {th }}$ percentile on the Finnish Test for Phonology (Kunnari et al., 2012) for the SSD group and at least at the $16^{\text {th }}$ percentile for the TD group. Furthermore, the children with SSD had to produce words inconsistently in an intra-word variability task in which the children were required to name 20 pictures three times during the same assessment session. A response was considered incorrect if there was substitution, omission, addition or distortion (except aspiration) of a consonant or vowel. The children's productions were coded as inconsistent when responses included at least two different response types with no matched adult target (Grunwell, 1992). The proportion of inconsistent responses was counted by dividing the number of words the child produced variably with no correct forms by the total number of target words the child named three times during the assessment, and multiplying the result by 100 . Finally, all the participants had to spontaneously use syllable-initial /p, t, k/.

Initially, parents of 45 children with SSD indicated their interest in participating in the study. Of these children, 13 were excluded due to low receptive language skills and/or too restricted speech production skills. Subsequently, of the remaining 32 
To cite this article: Anna-Leena Martikainen, Tuula Savinainen-Makkonen, \& Sari Kunnari (2020). Speech inconsistency and its association with speech production, phonological awareness and nonword repetition skills. Clinical Linguistics \& Phonetics, DOI: 10.1080/02699206.2020.1827296

children, six were excluded for not producing $/ \mathrm{k} /$ and one for not producing the $/ \mathrm{t} /$ phoneme in their spontaneous speech, and one who failed a DDK task. The remaining 24 preschoolers with SSD aged 3;4-5;4 (11 girls and 13 boys) participated in the study. They were either followed up by their local child welfare centres or were on the waiting list for assessment by a speech and language therapist (SLT). The participants were not divided into subgroups, because there are no criteria for differential diagnosing of SSD in Finnish. A total of 31 peers with TD aged 3;2-5;4 (14 girls and 17 boys) were a subset of children from the study described in Martikainen et al. (2019). Descriptive statistics of the study groups are presented in Table 1 . The groups did not differ significantly in age, gender, or in receptive language skills ( $\mathrm{p}>.05$ ) based on MannWhitney U tests. In both study groups, parents were asked to complete a questionnaire in order to provide case history information.

Table 1. Demographic and summary data for inclusion criteria for children with speech sound disorder (SSD) and children with typical speech and language development (TD).

\begin{tabular}{lcc}
\hline & Children with SSD & Children with TD \\
\hline Total, n & 24 & 31 \\
Age in months, mean & $53.7(6.9)$ & $52.3(7.4)$ \\
Gender, boys/girls & $13 / 11$ & $17 / 14$ \\
RDLS III, mean & $101.9(9.2)$ & $103.7(9.6)$ \\
ROWPVT, mean & $82.2(21.3)$ & $77.5(19.0)$ \\
Phonology test, mean & $3.4(4.2)$ & $66.2(23.5)$ \\
Inconsistency, median (IQR) & $30.0(11.3-44.3)$ & $5.0(0-5.3)$
\end{tabular}

Note. Standard deviations are in parentheses. RDLS III = The Reynell Developmental Language Scales III, Comprehension Scales, standard score ( $M=100, \mathrm{SD}=15)$; ROWPVT = Receptive One-Word Picture Vocabulary Test, raw score out of 190; Phonology Test $=$ percentile of the Finnish Test for Phonology; Inconsistency $=$ Proportion of inconsistent response types in the intra-word variability task; IQR = Interquartile range. 
To cite this article: Anna-Leena Martikainen, Tuula Savinainen-Makkonen, \& Sari Kunnari (2020). Speech inconsistency and its association with speech production, phonological awareness and nonword repetition skills. Clinical Linguistics \& Phonetics, DOI: 10.1080/02699206.2020.1827296

All study procedures were approved by the Research Ethics Committee of the Northern Savo Hospital District and the local Head of the Child Services. Parents provided informed written consent for their children to participate in the study.

\section{Data collection and procedure}

Participants were individually assessed either at the private clinic of the first author, at the child's daycare centre or at home, depending on the timetable or logistical issues of the families. Sessions were recorded using a video recorder (Canon Legria HF G25) with a microphone (Sennheiser ME 4) and a digital voice recorder (Olympus LS-11, Linear PCM recorder).

Speech production skills. The Finnish Test for Phonology (Kunnari et al., 2012), a single-word picture naming task normed for children between ages 2;0 and 6;11, was administered and a Percentage of Phonemes Correct (hereafter phonPPC; Shriberg, Austin, Lewis, McSweeny, \& Wilson, 1997) calculated for each participant.

Each child performed a DDK task in which they produced a trisyllabic sequence /pataka/, modelled by the examiner, as quickly and accurately as possible. They did 1-3 training trials, as required. A finger doll was used to motivate the child and to demonstrate how long s/he should continue repeating the sequence. As most participants were young and/or had SSD and thus might find the task difficult, the task was attempted only twice in order to avoid fatigue. The first four analysable /pataka/ sequences $(4$ sequences of $/$ pataka/ = DDK trial) in both strings of repetitions were phonetically transcribed (i.e. substitutions, omissions and distortions except aspiration of consonants were considered as errors, vowel deviations were ignored) using the acoustical analysis programme Praat (Boersma \& Weenink, 2020). When analysing 
To cite this article: Anna-Leena Martikainen, Tuula Savinainen-Makkonen, \& Sari Kunnari (2020). Speech inconsistency and its association with speech production, phonological awareness and nonword repetition skills. Clinical Linguistics \& Phonetics, DOI: 10.1080/02699206.2020.1827296

DDK accuracy and consistency, the trial with more correct realisations of /pataka/ was selected. The children's better DDK trial was classified either as consistently correct, consistently incorrect or as a variable response. Furthermore, DDK accuracy was determined by recording the total number of correct realisations of the /pataka/ sequences in the trial. DDK accuracy (hereafter DDKacc) scores varied from 0 to 4 so that a score was 0 when none of the trisyllabic sequences were correct and 4 when all of the sequences were correct. DDK consistency (hereafter DDKcons) was analysed by recording the total number of different types of realisations of /pataka/ in the trial. Consistency scores varied from 1 to 4 such that the score was 1 when all the sequences were the same, regardless of correctness of productions, and 4 when all four sequences differed from one another.

Phonological awareness. Two measures of phonological awareness were administered: (1) a Rhyme and initial syllable awareness task (adapted from Silvén, Niemi, \& Voeten, 2002); (2) a Syllabic segmentation task (adapted from Mäkinen, 2004). The Rhyme and initial syllable awareness task consisted of four practice items, and five testing items for rhyming and five for initial syllable awareness. The words used were bisyllabic, except for one series of single-syllable words in the rhyming task (Appendix 1). A child was presented a set of three pictures which recorded names s/he listened to through headphones. In the rhyme task, s/he was asked to point out which two words sound similar, and in the onset matching task, which two words started with the same syllable. The task was scored at the time of the testing.

In the Syllabic segmentation task, three practice words and 10 experiment words of two to five syllables were listened to through headphones (Appendix 2). A child was asked to say a given word and simultaneously segment it to syllables by tapping. A trial was also accepted if the child said the word so that the separate syllables could be heard 
To cite this article: Anna-Leena Martikainen, Tuula Savinainen-Makkonen, \& Sari Kunnari (2020). Speech inconsistency and its association with speech production, phonological awareness and nonword repetition skills. Clinical Linguistics \& Phonetics, DOI: 10.1080/02699206.2020.1827296

with no tapping. Only the number of syllables was acknowledged, not the correctness of articulation. The responses were scored online but later reviewed and verified from video recordings.

During the practice items the examiner gave explicit feedback and tried to help the child to focus on similarities between sound structures, but during the experimental items only supportive feedback was given. Each item of the phonological awareness tasks was scored as correct or incorrect. The total score for both tasks was the number of correct responses out of 10 items.

Nonword repetition. NWR was measured by two practice nonwords and ten 2-4syllabic nonwords (Appendix 3) selected from the Finnish Nonword Repetition Test (Kunnari, Tolonen \& Chiat, 2011). All the nonwords followed Finnish phonotactics and were constructed to exclude late-emerging consonants and vowels (Kunnari et al., 2012). In an attempt to reduce challenges associated with the motoric component of speech production, only syllable structures of CV, CVV and CVC (consonant geminates) were included in the nonwords. To analyse production of nonwords, the PPC score was calculated (i.e., substitution and deletion of the phoneme was considered as an error). Expected phonological patterns or articulatory errors (i.e. when at least $75 \%$ of productions of a target consonant or vowel were similarly incorrectly realised in the Finnish Test of Phonology, in a spontaneous speech sample, in the intra-word variability measure and in the Nonword repetition task), were not counted as incorrect.

\section{Reliability}

All speech samples were transcribed by the same SLT using the video recordings and confirming by the audio recording if necessary. In order to examine inter-judge transcription reliability, another experienced and certified SLT independently 
To cite this article: Anna-Leena Martikainen, Tuula Savinainen-Makkonen, \& Sari Kunnari (2020). Speech inconsistency and its association with speech production, phonological awareness and nonword repetition skills. Clinical Linguistics \& Phonetics, DOI: 10.1080/02699206.2020.1827296

transcribed a randomly selected $10 \%$ of the samples of the Finnish Test for Phonology, spontaneous speech, the intra-word variability task and NWR. Point-to-point inter-rater reliability ranged from $86 \%$ to $100 \%$, with a mean of $94 \%$. Two other SLTs carried out reliability analysis from a randomly selected $10 \%$ of the rest of the recordings: one for the DDK-task and another for the Syllable segmentation. Inter-rater reliability was $98 \%$. Intra-rater reliability was assessed on a randomly selected $10 \%$ of all the data and ranged from $86 \%$ to $100 \%$, with a mean of $96 \%$.

\section{Statistical analysis}

Statistical tests were computed with SPSS for windows (25.0, SPSS Inc.). Nonparametric statistical analysis for comparisons was used, as not all the data showed normal distribution. Descriptive statistics with median, interquartile range (IQR) and range were reported to present rates of speech productions skills (PhonPPC, DDKacc, DDKcons), phonological awareness (Rhyme and initial syllable awareness, Syllable segmentation) and NWR both in the SSD and the TD groups. Non-parametric MannWhitney U tests were used to test pairwise comparisons between the study groups. Correlations between the participants' speech inconsistency scores, which were obtained from the assessment to confirm their suitability for inclusion, and speech production, phonological awareness and NWR skills were calculated using Spearman's rho correlation coefficients. In addition, in order to acquire further insight into the participants' speech processing skills, which may be associated with the occurrence of speech inconsistency, correlations of NWR with speech production and phonological awareness skills were calculated. Thereafter the specificity of the relationships was analysed by age-adjusted Spearman's correlation in both study groups. 
To cite this article: Anna-Leena Martikainen, Tuula Savinainen-Makkonen, \& Sari Kunnari (2020). Speech inconsistency and its association with speech production, phonological awareness and nonword repetition skills. Clinical Linguistics \& Phonetics, DOI: 10.1080/02699206.2020.1827296

\section{Results}

\section{Speech production skills}

Overall speech accuracy of the children with TD was higher than among the children with SSD, as they produced more correct phonemes on the Phonology test (median 95.0) than the children with SSD (median 81.0; $\mathrm{U}=17.5, \mathrm{p}<.001$; Table 2). For the DDK task, the children with TD most typically produced four /pataka/ sequences consistently correctly, although the proportion of variably produced /pataka/ sequences was also rather high, $42 \%$ (Table 3). One third of the children with SSD produced /pataka/ sequences consistently correctly and the others either variably or consistently incorrectly. When considering accuracy of DDK trials, the children with TD more frequently produced correct /pataka/ sequences than the children with SSD (U $=239.50$, $\mathrm{p}<.05)$. With regard to consistency of DDK trials, in which both consistently correct and consistently incorrect productions were considered, no group differences were found $(\mathrm{U}=468.00, \mathrm{p}>.05)$.

Among the children with TD, their overall speech production accuracy was negatively correlated with speech inconsistency (Table 4). That is, the more accurate they were on the Phonology Test, the less inconsistent they were on the intra-word variability measure. For the children with SSD, higher accuracy both in overall speech production and in /pataka/ sequences were negatively correlated with variable speech production (Table 4). All associations remained even when age-related variance was removed. No other correlations were observed. 
To cite this article: Anna-Leena Martikainen, Tuula Savinainen-Makkonen, \& Sari Kunnari (2020). Speech inconsistency and its association with speech production, phonological awareness and nonword repetition skills. Clinical Linguistics \& Phonetics, DOI: 10.1080/02699206.2020.1827296

Table 2. Scores on the measures of speech production skills, phonological awareness and nonword repetition in the children with speech sound disorder (SSD) and with typical speech and language development (TD).

\begin{tabular}{|c|c|c|c|c|c|c|}
\hline & \multicolumn{3}{|c|}{ Children with SSD } & \multicolumn{3}{|c|}{ Children with TD } \\
\hline & Median & IQR & Range & Median & IQR & Range \\
\hline PhonPPC & 81.0 & $75.3-86.7$ & 67-92 & 95.0 & $93.0-98.0$ & $83-100$ \\
\hline DDKacc & 2.0 & $0.0-4.0$ & $0-4$ & 4.0 & $3.0-4.0$ & $0-4$ \\
\hline DDKcons & 2.0 & $1.0-3.0$ & $1-4$ & 1.0 & $1.0-2.0$ & $1-4$ \\
\hline Rhyme & 6.0 & $4.0-7.0$ & $0-10$ & 7.0 & $4.0-8.0$ & $3-10$ \\
\hline Syllables & 5.0 & $3.3-8.8$ & $0-9$ & 8.0 & $4.0-10.0$ & $0-10$ \\
\hline NWR & 93.0 & $83.3-98.0$ & $70-100$ & 98.0 & $98.0-100$ & $93-100$ \\
\hline
\end{tabular}

Note. $\mathrm{IQR}=$ Interquartile range; PhonPPC $=$ PPC on the Finnish Test for Phonology; DDKacc $=$ Accuracy of /pataka/ sequences; DDKcons = Consistency of /pataka/ sequences; Rhyme = Rhyme and initial syllable awareness; Syllables $=$ Syllable segmentation; NWR $=$ Nonword repetition.

Table 3. The proportion of each response type in the DDK-task (i.e. /pataka/ sequences) for the children with speech sound disorder (SSD) and the children with typical speech and language development (TD).

$$
\text { ( } \mathrm{N}=24)
$$

$$
(\mathrm{N}=31)
$$

\begin{tabular}{lcccc}
\cline { 2 - 3 } Response type & $\%$ & $(\mathrm{n})$ & $\%$ & $(\mathrm{n})$ \\
\hline correctly & 33 & $(8)$ & 58 & $(18)$ \\
incorrectly & 8 & $(2)$ & 0 & $(0)$ \\
variably & 58 & $(14)$ & 42 & $(13)$
\end{tabular}


To cite this article: Anna-Leena Martikainen, Tuula Savinainen-Makkonen, \& Sari Kunnari (2020). Speech inconsistency and its association with speech production, phonological awareness and nonword repetition skills. Clinical Linguistics \& Phonetics, DOI: 10.1080/02699206.2020.1827296

\section{Phonological awareness}

Median score in the Rhyme and initial syllable awareness task was almost the same for the two study groups: 7.0 in the children with TD and 6.0 in the children with DDS, whereas in the Syllable segmentation task the scores were 8.0 and 5.0, respectively (Table 2). No statistically significant differences were observed between the study groups (Rhyme and initial syllable awareness $U=303.0, \mathrm{p}>.05$; Syllable segmentation $\mathrm{U}=277.0, \mathrm{p}>.05)$

The rhyme and initial syllable awareness, but not the syllable segmentation, associated with inconsistent speech production among the children with TD even after age-related variance was controlled for (Table 4). No association was found between phonological awareness skills of the children with SSD and their inconsistent speech production.

\section{Nonword repetition}

Productions of the children with TD were more accurate in the NWR task (median 98.0) than those of the children with SSD (median 93.0; $U=141.50, p<.001$; Table 2).

Among the children with TD and the children with SSD, more accurate NWR skills were correlated with less inconsistent speech production (Table 4). Furthermore, NWR was positively correlated with overall speech accuracy among both study groups, and also with accuracy of /pataka/ sequences among the children with SSD (Table 4). All these associations remained after the effects of age were removed. No other correlations were observed. 
To cite this article: Anna-Leena Martikainen, Tuula Savinainen-Makkonen, \& Sari Kunnari (2020). Speech inconsistency and its association with speech production, phonological awareness and nonword repetition skills. Clinical Linguistics \& Phonetics, DOI: 10.1080/02699206.2020.1827296

Table 4. Spearman's correlation coefficients, and partial correlations (in parentheses) controlling for age of the participants, between speech inconsistency and the participants' speech production, phonological awareness and nonword repetition skills in the children with speech sound disorder (SSD) and the children with typical speech and language development (TD).

\begin{tabular}{|c|c|c|c|c|}
\hline & \multicolumn{2}{|c|}{ Inconsistency } & \multicolumn{2}{|c|}{ NWR } \\
\hline & SSD & TD & SSD & TD \\
\hline \multirow[t]{2}{*}{ Inconsistency } & - & - & $-0.53 * *$ & $-0.50 * *$ \\
\hline & - & - & $\left(-0.43^{*}\right)$ & $(-0.51) * *$ \\
\hline \multirow[t]{2}{*}{ PhonPPC } & $-0.72 * * *$ & $-0.69 * * *$ & $0.70 * * *$ & $0.44 *$ \\
\hline & $(-0.67)^{* *}$ & $(-0.58)^{* *}$ & $(0.64)^{* *}$ & $(0.48)^{*}$ \\
\hline \multirow[t]{2}{*}{ DDKacc } & $-0.46^{*}$ & -0.04 & $0.58 * *$ & 0.07 \\
\hline & $(-0.47)^{*}$ & $(0.06)$ & $(0.61)^{* *}$ & $(0.05)$ \\
\hline \multirow[t]{2}{*}{ DDKcons } & 0.23 & -0.16 & -0.16 & -0.07 \\
\hline & $(0.37)$ & $(-0.31)$ & $(-0.31)$ & $(-0.05)$ \\
\hline \multirow[t]{2}{*}{ Rhyme } & 0.06 & $-0.61 * * *$ & 0.12 & 0.25 \\
\hline & $(0.05)$ & $(-0.47 *)$ & $(0.15)$ & $(0.23)$ \\
\hline \multirow[t]{2}{*}{ Syllables } & -0.30 & -0.20 & 0.35 & 0.29 \\
\hline & $(-0.17)$ & $(-0.07)$ & $(0.21)$ & $(0.27)$ \\
\hline \multirow[t]{2}{*}{ NWR } & $-0.53 * *$ & $-0.50 * *$ & - & - \\
\hline & $\left(-0.43^{*}\right)$ & $(-0.51)^{* *}$ & - & - \\
\hline
\end{tabular}

Note. Inconsistency $=$ Proportion of inconsistent response types in the intra-word variability task; PhonPPC $=$ PPC on the Finnish Test for Phonology; DDKacc $=$ Accuracy of $/$ pataka/ sequences; DDKcons $=$ Consistency of /pataka/ sequences; Rhyme $=$ Rhyme and initial syllable awareness; Syllables $=$ Syllable segmentation; NWR = Nonword repetition .

$* \mathrm{p}<0.05, * * \mathrm{p}<0.01, * * * \mathrm{p}<0.001$. 
To cite this article: Anna-Leena Martikainen, Tuula Savinainen-Makkonen, \& Sari Kunnari (2020). Speech inconsistency and its association with speech production, phonological awareness and nonword repetition skills. Clinical Linguistics \& Phonetics, DOI: 10.1080/02699206.2020.1827296

\section{Discussion}

The aim of our study was to investigate possible associations between inconsistent speech and children's speech production skills, phonological awareness and NWR in Finnish children with TD and children with SSD aged 3;2-5;4. We hypothesised that the children with TD would outperform the children with SSD on all measures of speech production, phonological awareness and NWR skills. Furthermore, we supposed that these skills would be negatively correlated with inconsistent speech production among both study groups.

\section{Speech production skills and its association with speech inconsistency}

As we hypothesised, overall speech production skills of the children with SSD were less accurate compared to their peers with TD matched for age, gender, and receptive skills. Both among the children with TD and children with SSD, inconsistency of speech was associated with overall speech production skills even when the contribution of age was accounted for. This could indicate a motoric origin of speech inconsistency. In other words, the more accurately a child produced the consonants and vowels on the Phonology Test, the more consistent s/he was on the variability measure. This finding sounds logical, as the tasks were of the same type: speech production was elicited by picture naming. To the best of our knowledge, the relationship between speech inconsistency and performance in an articulatory/phonology test has not previously been studied among children with SSD. The findings of Martikainen et al. (2019) are in line with those of the current study, as they reported that the more accurate children's spontaneous speech was, the more consistent they were on the intra-word variability measure. However, regarding the children with TD, our result is contrary to that of Macrae and Sosa (2015), who found no correlation between an articulatory test (GFTA- 
To cite this article: Anna-Leena Martikainen, Tuula Savinainen-Makkonen, \& Sari Kunnari (2020). Speech inconsistency and its association with speech production, phonological awareness and nonword repetition skills. Clinical Linguistics \& Phonetics, DOI: 10.1080/02699206.2020.1827296

2) and inconsistency of speech in children aged 2;6 to 4;2. One reason for the discrepancy might be, as Macrae and Sosa mentioned themselves, that the test was not sensitive enough to bring out differences between the participants with TD. We used the Finnish Test for Phonology, which is composed of 90 one- to five-syllable words and thus possibly provides more opportunities for variability in production. Another reason for the discrepancy may lie in the transcription level used. Macrae and Sosa conducted broad transcription, whereas in the present study distortions were also included in the analysis. From a motoric point of view, distortion of sounds in particular, has been reported to reflect possible weaknesses at the level of speech motor planning and/or /programming (Terband, et al., 2011).

On the DDK task, the children with SSD performed variably. About one third of them had no difficulties in repeating four/pataka/ sequences, but most of them produced the sequences inconsistently. The children with TD mostly produced consistently correct /pataka/ sequences, but the proportion of variable sequences was surprisingly high, $42 \%$. This is contrary to the finding of Williams and Stackhouse (2000), who reported that among 3-4-year old children with TD most of the responses were consistent (albeit possibly incorrect). The high PPCs on the Phonology Test (median 95\%) and low inconsistency of the children with TD in the current study, might be explained by the TD group's good speech production skills. One likely explanation for their variable performance is that in that age range, speech motor control is still vulnerable under a demanding situation. It might be that the children with TD had confidence in their speech skills, and they tried to produce sequences rapidly, at the expense of accuracy. Another explanation may relate to methodological factors. We anticipated that at least younger children with SSD might not be willing to keep on repeating /pataka/ sequences but rather would give up after a few attempts (which, in 
To cite this article: Anna-Leena Martikainen, Tuula Savinainen-Makkonen, \& Sari Kunnari (2020). Speech inconsistency and its association with speech production, phonological awareness and nonword repetition skills. Clinical Linguistics \& Phonetics, DOI: 10.1080/02699206.2020.1827296

fact, proved to be true). Thus, only two strings of /pataka/ sequences were chosen for closer inspection. This was not necessarily of advantage to the children with TD, as they might have been able to try to hold on longer and eventually achieve accurate production.

Contrary to our hypothesis, accuracy of the /pataka/ sequences was not correlated to speech inconsistency among the children with TD, which may be explained by variable production. In the case of the children with SSD, an expected negative connection was found, i.e. the less accurate /pataka/ sequences they produced, the higher were their inconsistent scores. This, again, indicates a motoric explanation for speech inconsistency, as repetition of (non-)meaningful syllable sequences is thought to reflect predominantly the neuromotor aspects of speech production (Terband et al., 2019).

\section{Phonological awareness and its association with speech inconsistency}

In contrast to a number of studies (Anthony et al., 2011; Brosseau-Lapré \& Roepke, 2019; Larrivee \& Catts, 1999; McNeill et al., 2009; McNeill et al., 2017; Peterson et al., 2009; Preston \& Edwards, 2010) and our hypothesis, no difference in phonological awareness between the study groups was observed. If one assumes that phonological awareness skills are related to underlying phonological representations (Anthony et al., 2011; Elbro et al., 1998; Rvachew, 2006; Sutherland \& Gillon, 2007), it could indirectly be concluded that, at a group level, phonological representations among the participants of our study were similar. This is possible, as a robustness of phonological representations is reported to relate to receptive vocabulary growth (Metsala, 1999; Preston \& Edwards, 2010), and receptive language skills were equal between the groups of the current study. 
To cite this article: Anna-Leena Martikainen, Tuula Savinainen-Makkonen, \& Sari Kunnari (2020). Speech inconsistency and its association with speech production, phonological awareness and nonword repetition skills. Clinical Linguistics \& Phonetics, DOI: 10.1080/02699206.2020.1827296

However, when we conducted correlation analyses, a somewhat different picture emerged. The rhyme and initial syllable awareness of the children with TD correlated negatively with speech inconsistency, as we hypothesised. That is, the more aware the children with TD were of the rhymes and onsets of the words, the less inconsistent they were on the intra-word variability measure. Furthermore, as Spearman's correlation between the rhyme and initial syllable awareness and speech inconsistency was -0.61 and decreased with age-adjusted correlation to -0.47 , it can be assumed that in the children with TD the development of low-level phonological awareness skills was in progress. On the other hand, against our hypothesis, no correlation was observed between syllable segmentation and speech inconsistency. This could imply that the segmentation ability was still so fragile that the performance varied in a such way that no systematic relationship could yet have been formed. This is supported by findings that the development of phonological awareness proceeds from larger units to smaller ones and from perceiving segments to an ability to manipulate them (Carroll et al., 2003). Among the children with SSD, our hypothesis turned out to be incorrect, as there was no correlation between phonological awareness and inconsistent speech production. This might refer to a high variability in performance, which in turn could reflect a delayed trajectory of the skills.

So, although the children performed similarly in the phonological awareness tasks at the group level, the correlational analyses indicated that the skills might be more developed among the children with TD. Thus, the first impression concerning similar phonological representations between the children with TD and the children with SSD may need to be revised. As in some previous studies of the association between children's lower vocabulary knowledge and higher speech inconsistency (Dodd et al., 2005; Macrae et al., 2014; Macrae \& Sosa, 2015, Martikainen et al., 2020), we 
To cite this article: Anna-Leena Martikainen, Tuula Savinainen-Makkonen, \& Sari Kunnari (2020). Speech inconsistency and its association with speech production, phonological awareness and nonword repetition skills. Clinical Linguistics \& Phonetics, DOI: 10.1080/02699206.2020.1827296

can assume that phonological representations, at least among some of the children with SSD, were more poorly specified compared to the children with TD. This was further echoed in speech inconsistency. With respect to the children with TD, however, the result is contrary to that of Martikainen et al. $(2019,2020)$, who found no correlation between speech inconsistency and children's vocabulary among children aged 3 to 6 . An explanation for the contradictory findings might lie in the different measures used in the studies. There are some indications that in Finnish, multi-syllabic word structures might decrease the pressure for more detailed storing of lexical items in memory (Martikainen et al., 2019, 2020; Silvén et al., 2002). Therefore, vocabulary tests may not be sensitive enough to bring out associations, unlike phonological awareness tasks which tap smaller sub-lexical units.

\section{NWR and its association with speech inconsistency}

As anticipated, the children with TD repeated the nonwords more accurately than the children with SSD, although distortions and systematic substitutions were not taken into account in the analysis. Aiming to decrease the possible role of speech motor challenges for the children with SSD, the syllable structures of the nonwords were mainly early developing $\mathrm{CV}(\mathrm{V})$ with a few $\mathrm{CVC}$ structures. The task was very easy for the children with TD (median PPC was 98\%), but even among the children with SSD the median percent of PPC was relatively high (93\%), which means that they produced inconsistent errors only rarely.

In line with our hypothesis, NWR was correlated with speech inconsistency in both study groups. The more accurately the children could produce nonwords, the less inconsistent they were on the intra-word variability measure. Concerning the children with SSD, the result is in accordance with that of Macrae et al. (2014), who contemplated that their finding supported the proposal of inconsistent speech errors 
To cite this article: Anna-Leena Martikainen, Tuula Savinainen-Makkonen, \& Sari Kunnari (2020). Speech inconsistency and its association with speech production, phonological awareness and nonword repetition skills. Clinical Linguistics \& Phonetics, DOI: 10.1080/02699206.2020.1827296

deriving from indistinct phonological representations. However, in order to provide a broader view of the children's speech processing skills in the current study, we calculated correlations between NWR and the other speech production and phonological awareness tasks. As NWR is often used to reveal possible impairments in linguistic processing (Coady \& Evans, 2008, see for a review), it could be expected to correlate especially with linguistic skills such as phonological awareness. Our final hypothesis was only partly confirmed, as our findings highlighted the role of speech production skills in NWR in both the study groups, whereas no correlation was found with phonological awareness. This obviously calls for further study in order to investigate the relationships in depth, but it appears that in the current study, components of the speech motor system were indicated to have a substantial role in speech inconsistency in the children with SSD.

\section{Conclusions}

This study shows that inaccuracy in speech production and NWR is associated with more variable speech among children with SSD highlighting the possible role of motor components of inconsistent speech production. In addition, the findings indicate that the development of phonological awareness among the children with SSD may be delayed, although no correlation was found with inconsistent speech production. We interpret these findings to reflect the multi-factorial nature of developmental speech sound disorders. Thus, a psycholinguistic/process-oriented approach (Stackhouse \& Wells, 1997; Terband et al., 2019) to assessment and treatment planning of SSD may be needed in order to provide useful tools to SLTs for revealing the underlying factors of an impairment.

Further study with a larger sample of Finnish children with SSD would enable division of the participants into different sub-groups according the type of their speech 
To cite this article: Anna-Leena Martikainen, Tuula Savinainen-Makkonen, \& Sari Kunnari (2020). Speech inconsistency and its association with speech production, phonological awareness and nonword repetition skills. Clinical Linguistics \& Phonetics, DOI: 10.1080/02699206.2020.1827296

errors, and thus make it possible to provide more precise information about processes underlying inconsistent speech. Furthermore, in order to examine NWR skills among children with SSD, target nonwords only including rarely misarticulated speech sounds (like in the Syllable Repetition Task by Shriberg et al, 2009) would clarify the scoring procedure and thus minimize the confusing effect of impaired speech production on interpretation of findings. Finally, in the current study we only used tasks which assessed phonological representations implicitly. Direct methods presented in the literature (e.g. Anthony et al, 2011) might be useful in order to throw more light on the role of phonological representations in inconsistent speech production.

\section{Declaration of Conflicting Interest}

The authors report no conflicts of interest.

\section{References}

Aalto, E., Saaristo-Helin, K., \& Stolt, S. (2019). Phonological development of Finnish speaking children at 3;6 and associations to previous and simultaneous lexical ability. Clinical Linguistics \& Phonetics. Advance online publication https://doi.org/10.1080/02699206.2019.1681517.

American Speech-Language-Hearing Association. (2007). Childhood apraxia of speech [Position statement]. Retrieved from http://www.asha.org/policy/PS2007-00277/

Anthony, J. L., Aghara, R. G., Dunkelberger, M. J., Anthony, T. I., Williams, J. M., \& Zhang, Z. (2011). What factors place children with speech sound disorders at risk for reading problems? American Journal of Speech-Language Pathology, $20,146-160$. 
To cite this article: Anna-Leena Martikainen, Tuula Savinainen-Makkonen, \& Sari Kunnari (2020). Speech inconsistency and its association with speech production, phonological awareness and nonword repetition skills. Clinical Linguistics \& Phonetics, DOI: 10.1080/02699206.2020.1827296

Boersma, P., \& Weenink, D. (2020). Praat: doing phonetics by computer (Version 6.1.12). Available online at: http://www.fon.hum.uva.nl/praat/.

Brosseau-Lapré, F., \& Roepke, E. (2019). Speech errors and phonological awareness in children ages 4 and 5 years with and without speech sound disorder. Journal of Speech, Language \& Hearing Research, 62, 3276-3289.

Carroll, J. M., Snowling, M. J., Stevenson, J., \& Hulme, C. (2003). The development of phonological awareness in preschool children. Developmental Psychology, 39, 913-923.

Coady, J. A., \& Evans, J. L. (2008). Uses and interpretations of non-word repetition tasks in children with and without specific language impairments (SLI). International Journal of Language \& Communication Disorders, 43, 1-40.

Diepeveen, S., van Haaften, L., Terband, H., de Swart, B., \& Maassen, B. (2019). A standardized protocol for maximum repetition rate assessment in children. Folia Phoniatrica \& Logopaedica, 71, 238-250.

Dodd, B., Holm, A., Crosbie, S., \& McCormack, P. (2005). Differential diagnosis of phonological disorders. In B. Dodd (Ed.), Differential diagnosis and treatment of children with speech disorders (2nd ed.) (pp. 44-70). London, UK: Whurr Publishers Ltd.

Edwards, J., Beckman, M. E., \& Munson, B. (2004). The interaction between vocabulary size and phonotactic probability effects on children's production accuracy and fluency in nonword repetition. Journal of Speech, Language, and Hearing Research, 47, 421-436.

Elbro, C., Borstrom, I., \& Petersen, D. K. (1998). Predicting dyslexia from kindergarten: The importance of distinctness of phonological representations of lexical items. Reading Research Quarterly, 33, 36-60. 
To cite this article: Anna-Leena Martikainen, Tuula Savinainen-Makkonen, \& Sari Kunnari (2020). Speech inconsistency and its association with speech production, phonological awareness and nonword repetition skills. Clinical Linguistics \& Phonetics, DOI: 10.1080/02699206.2020.1827296

Gathercole, S. E., \& Baddeley, A. D. (1989). Evaluation of the role of phonological STM in the development of vocabulary in children: A longitudinal study. Journal of Memory and Language, 28, 200-213.

Goffman, L., Gerken, L., \& Lucchesi, J. (2007). Relations between segmental and motor variability in prosodically complex nonword sequences. Journal of Speech, Language \& Hearing Research, 50, 444-458.

Green, J. R., Moore, C. A., \& Reilly, K. J. (2002). The sequential development of jaw and lip control for speech. Journal of Speech, Language, and Hearing Research, $45,66-79$.

Grunwell, P. (1992). Assessment of child phonology in the clinical context. In C. A. Ferguson, L. Menn, \& C. Stoel-Gammon (Eds.), Phonological development: Models, research, implications (pp. 457-483). Timonium, Maryland: York Press.

Hadders-Algra, M. (2018). Early human motor development: From variation to the ability to vary and adapt. Neuroscience and Biobehavioral Review. 90, 411-427.

Holm, A., Crosbie, S., \& Dodd, B. (2007). Differentiating normal variability from inconsistency in children's speech: Normative data. International Journal of Language \& Communication Disorders, 42, 467-486.

Holm, A., Farrier, F., \& Dodd, B. (2008). Phonological awareness, reading accuracy and spelling ability of children with inconsistent phonological disorder. International Journal of Language \& Communication Disorders, 43, 300322. Karlsson, F. (1983). Suomen kielen äänne- ja muotorakenne [Finnish phonology and morphology]. Porvoo, Finland: WSOY. 
To cite this article: Anna-Leena Martikainen, Tuula Savinainen-Makkonen, \& Sari Kunnari (2020). Speech inconsistency and its association with speech production, phonological awareness and nonword repetition skills. Clinical Linguistics \& Phonetics, DOI: 10.1080/02699206.2020.1827296

Kortesmaa, M., Heimonen, K., Merikoski, H., Warma, M-L., \& Varpela, V. (2001). Reynellin kielellisen kehityksen testi [Reynell developmental language scales]. Helsinki, Finland: Psykologien Kustannus.

Kunnari, S. (2000). Characteristics of early lexical and phonological development in children acquiring Finnish (Doctoral Dissertion). Acta Universitatis Ouluensis, B34. Oulu, Finland: Oulu University Press.

Kunnari, S., Savinainen-Makkonen, T., \& Saaristo-Helin, K. (2012). Fonologiatesti. Lasten äänteellisen kehityksen arviointimenetelmä [Test for Phonology]. Jyväskylä, Finland: Niilo Mäki Instituutti.

Kunnari, S., Tolonen, A-K., \& Chiat, S. (2011). Finnish Nonword Repetition Test (FNRT). (The unpublished test developed within COST Action IS0804, www.bi-sli.org).

Larrivee, L. S., \& Catts, H. W. (1999). Early reading achievement in children with expressive phonological disorders. American Journal of Speech-Language Pathology, 8, 118-128.

Macrae, T. (2013). Lexical and child-related factors in word variability and accuracy in infants. Clinical Linguistics \& Phonetics, 27, 497-507.

Macrae, T., \& Sosa, A. V. (2015). Predictors of token-to-token inconsistency in preschool children with typical speech-language development. Clinical Linguistics \& Phonetics, 29, 922-937.

Macrae, T., Tyler, A. A., \& Lewis, K. E. (2014). Lexical and phonological variability in preschool children with speech sound disorder. American Journal of SpeechLanguage Pathology, 23, 27-35. 
To cite this article: Anna-Leena Martikainen, Tuula Savinainen-Makkonen, \& Sari Kunnari (2020). Speech inconsistency and its association with speech production, phonological awareness and nonword repetition skills. Clinical Linguistics \& Phonetics, DOI: 10.1080/02699206.2020.1827296

Martikainen, A-L., Savinainen-Makkonen, T., \& Kunnari, S. (2019). Intra-word consistency and accuracy in Finnish children aged 3-6 years. Clinical Linguistics \& Phonetics, 33, 815-830.

Martikainen, A-L., Savinainen-Makkonen, T., Laukkanen-Nevala, P., \& Kunnari, S. (2019). Intra-word accuracy and consistency in Finnish-speaking children with speech sound disorder compared to their typically developing peers. Clinical Linguistics \& Phonetics. Advance online publication https://doi.org/10.1080/02699206.2019.1696610.

Martin, N. A., \& Brownell, R. (2010b). Receptive One-Word Picture Vocabulary Test4, Finnish version: S. Kunnari \& T. Välimaa; In validation. Novato, CA: Academic Therapy Publications.

McNeill, B. C., Gillon, G. T., \& Dodd, B. (2009). Phonological awareness and early reading development in childhood apraxia of speech (CAS). International Journal of Language \& Communication Disorders, 44, 175-192.

McNeill, B. C., Wolter, J., \& Gillon, G. T. (2017). A comparison of the metalinguistic performance and spelling development of children with inconsistent speech sound disorder and their age-matched and reading-matched peers. American Journal of Speech-Language Pathology, 26, 456-468.

Metsala, J. L. (1999). Young children's phonological awareness and nonword repetition as a function of vocabulary development. Journal of Educational Psychology, $91,3-19$.

Metsala, J. L., \& Walley, A. C. (1998). Spoken vocabulary growth and the segmental restructuring of lexical representations: Precursors to phonemic awareness and early reading ability. In L. Metsala Jamie, \& L. C. Ehri (Eds.), Word recognition in beginning literacy (pp. 89-120). Mahwah, NJ: Erlbaum. 
To cite this article: Anna-Leena Martikainen, Tuula Savinainen-Makkonen, \& Sari Kunnari (2020). Speech inconsistency and its association with speech production, phonological awareness and nonword repetition skills. Clinical Linguistics \& Phonetics, DOI: 10.1080/02699206.2020.1827296

Murray, E., McCabe, P., Heard, R., \& Ballard, K. J. (2015). Differential diagnosis of children with suspected childhood apraxia of speech. Journal of Speech, Language, \& Hearing Research, 58, 43-60.

Mäkinen, M. (2002). Kummi 3. Lukemisen aika, leikin taika. Lukemisvalmiuksien arvioiminen ja harjoittaminen [Assessment and training of preliteracy skills]. Jyväskylä, Finland: Niilo Mäki Instituutti.

Peterson, R. L., Pennington, B. F., Shriberg, L. D., \& Boada, R. (2009). What influences literacy outcome in children with speech sound disorder? Journal of Speech, Language, and Hearing Research, 52, 1175-1188.

Preston, J. L., \& Edwards, M. L. (2009). Speed and accuracy of rapid speech output by adolescents with residual speech sound errors including rhotics. Clinical Linguistics \& Phonetics, 23, 301-318.

Preston, J., \& Edwards, M. L. (2010). Phonological awareness and types of sound errors in preschoolers with speech sound disorders. Journal of Speech, Language, and Hearing Research, 53, 4460.

Roid, G. H., Miller, L. J., Pomplun, M., \& Koch, C. (2013). Leiter International Performance Scale - Third Edition. Wood Dale, IL: Stoelting.

Rvachew, S. (2006). Longitudinal predictors of implicit phonological awareness skills. American Journal of Speech-Language Pathology, 15, 165-176.

Saaristo-Helin, K. (2009). Measuring phonological development: A follow-up study of five children acquiring Finnish. Language and Speech, 52, 55-77.

Shriberg, L. D., Austin, D., Lewis, B. A., McSweeny, J. L., \& Wilson, D. L. (1997). The percentage of consonants correct (PCC) metric: Extensions and reliability data. Journal of Speech, Language, and Hearing Research, 40, 708-722. 
To cite this article: Anna-Leena Martikainen, Tuula Savinainen-Makkonen, \& Sari Kunnari (2020). Speech inconsistency and its association with speech production, phonological awareness and nonword repetition skills. Clinical Linguistics \& Phonetics, DOI: 10.1080/02699206.2020.1827296

Shriberg, L. D., Lohmeier, H. L., Campbell, T. F., Dollaghan, C. A., Green, J. R., \& Moore, C. A. (2009). A nonword repetition task for speakers with misarticulations: The Syllable Repetition Task (SRT). Journal of Speech, Language, and Hearing Research, 52, 1189-1212.

Silvén, M., Niemi, P., \& Voeten, M. J. M. (2002). Do maternal interaction and early language predict phonological awareness in 3- to 4-year-olds? Cognitive Development, 17, 1133-1155.

Smith, A., \& Goffman, L. (1998). Stability and patterning of speech movement sequences in children and adults. Journal of Speech, Language, \& Hearing Research, 41, 18-30.

Sosa, A. V. (2015). Intraword variability in typical speech development. American Journal of Speech-Language Pathology, 24, 24-35.

Sosa, A. V., \& Stoel-Gammon, C. (2006). Patterns of intra-word phonological variability during the second year of life. Journal of Child Language, 33, 31-50.

Stackhouse, J., \& Wells, B. (1997). Children's speech and literacy difficulties: A psycholinguistic framework. London, UK: Whurr.

Sutherland, D., \& Gillon, G. T. (2007). Development of phonological representations and phonological awareness in children with speech impairment. International Journal of Language \& Communication Disorders, 42, 229-250.

Swingley, D., \& Aslin, R. N. (2000). Spoken word recognition and lexical representation in very young children. Cognition, 76, 147-166.

Terband, H., Maassen, B., van Lieshout, P., \& Nijland, L. (2011). Stability and composition of functional synergies for speech movements in children with developmental speech disorders. Journal of Communication Disorders, 44, 5974. 
To cite this article: Anna-Leena Martikainen, Tuula Savinainen-Makkonen, \& Sari Kunnari (2020). Speech inconsistency and its association with speech production, phonological awareness and nonword repetition skills. Clinical Linguistics \& Phonetics, DOI: 10.1080/02699206.2020.1827296

Terband, H., Maassen, B., \& Maas, E. (2019). A psycholinguistic framework for diagnosis and treatment planning of developmental speech disorders. Folia Phoniatrica \& Logopaedica, 71, 216-227.

Thoonen, G., Maassen, B., Gabreels, F., \& Schreuder, R. (1999). Validity of maximum performance tasks to diagnose motor speech disorders in children. Clinical Linguistics \& Phonetics, 13, 1-23.

Vuolo, J., \& Goffman, L. (2016). An exploratory study of the influence of load and practice on segmental and articulatory variability in children with speech sound disorders. Clinical Linguistics \& Phonetics, 31, 331-350.

Walley, A., Metsala, J., \& Garlock, V. (2003). Spoken vocabulary growth: Its role in the development of phoneme awareness and early reading ability. Reading and Writing, 16, 5-20.

Whiteside, S. P., Dobbin, R., \& Henry, L. (2003). Patterns of variability in voice onset time: a developmental study of motor speech skills in humans. Neuroscience Letters, 347, 29-32

Williams, P., \& Stackhouse, J. (2000). Rate, accuracy and consistency: Diadochokinetic performance of young, normally developing children. Clinical Linguistics \& Phonetics, 14, 267-293. 
To cite this article: Anna-Leena Martikainen, Tuula Savinainen-Makkonen, \& Sari Kunnari (2020). Speech inconsistency and its association with speech production, phonological awareness and nonword repetition skills. Clinical Linguistics \& Phonetics, DOI: 10.1080/02699206.2020.1827296

Appendix 1. Item overview in the rhyming and initial-syllable awareness task

Test items of rhyme

$\begin{array}{lll}\text { /pæ:/ head } & \text { /lu:/ bone } & \text { /ku:/ moon } \\ \text { /raha/ money } & \text { /kynæ/ pencil } & \text { /saha/ saw } \\ \text { /mys:y/ bonnet/ } & \text { pot:a/ potty } & \text { /rot:a/ rat } \\ \text { /luk:o/ lock } & \text { /kuk:o/ rooster/ } & \text { tat:i/ bolete } \\ \text { /hi:ri/ mouse } & \text { /ju:ri/ root } & \text { /mu:ri/ wall }\end{array}$

Test items of initial-syllable matching

$\begin{array}{lll}\text { /lintu/ bird } & \text { /tut:i/ pacifier } & \text { /lin:a/ castle } \\ \text { /palko/ pod } & \text { /pal:o/ ball } & \text { /kampa/ comb } \\ \text { /kæsi/ hand } & \text { /kæpy/ cone } & \text { /mato/ worm } \\ \text { /muki/ mug } & \text { /saha/ saw } & \text { /sade/ rain } \\ \text { /leija/ kite } & \text { /leipæ/ bread } & \text { /sieni/ mushroom }\end{array}$


To cite this article: Anna-Leena Martikainen, Tuula Savinainen-Makkonen, \& Sari Kunnari (2020). Speech inconsistency and its association with speech production, phonological awareness and nonword repetition skills. Clinical Linguistics \& Phonetics, DOI: 10.1080/02699206.2020.1827296

Appendix 2. Item overview in the syllable segmentation task.

Test items of syllable awareness:

$\begin{array}{ll}\text { /au.to/ } & \text { car } \\ \text { /pe.sæ/ } & \text { nest } \\ \text { /o.me.na/ } & \text { apple } \\ \text { /kei.ju.kai.nen/ } & \text { fairy } \\ \text { /mat.to/ } & \text { carpet } \\ \text { /len.to.ko.ne/ } & \text { airplane } \\ \text { /pal.kin.to/ } & \text { prize } \\ \text { /kei.nu/ } & \text { swing } \\ \text { /sa.la.ma/ } & \text { lightning } \\ \text { /kas.te.lu.kan.nu/ } & \text { watering can }\end{array}$


To cite this article: Anna-Leena Martikainen, Tuula Savinainen-Makkonen, \& Sari Kunnari (2020). Speech inconsistency and its association with speech production, phonological awareness and nonword repetition skills. Clinical Linguistics \& Phonetics, DOI: 10.1080/02699206.2020.1827296

Appendix 3. Item overview in the nonword repetition task.

\section{Test items of nonword repetition:}

lyy.ve

kii.ta.le

na.lu

ma.ka.lo.ne

pee.ku.sa

tum.mi.te.li

sil.lo.va

tu.mi.la

paa.su.va.ni

kik.ko 